\title{
8.2. Договоры о передаче исключительных прав на объекты промышленной собственности с участием социальных предприятий
}

\author{
(Б) Батmaxов П.П. \\ Институт государства и права РАН, г. Москва, Российская Федерация \\ Battakhov@mail.ru
}

\section{Аннотация}

В статье рассматриваются договорные конструкции, направленные на передачу исключительных прав на объекты промышленной собственности. Выявлена проблема договорного процесса при заключении договора о передаче комплекса исключительных прав. На основании исследования предложен ряд изменений в российские законы. Прежде всего, это касается договора коммерческой концессии. Автор предлагает внести изменения в ГК Российской Федерации путем дополнения статьи о коммерческой концессии правом организаций, который не ведут коммерческую деятельность, заключать на общих основаниях такие же договоры. Обоснована целесообразность применения классификации сделок на реальные и консенсуальные в отношении данного договора. Исследуется особенности о передаче комплекса исключительных прав на объекты промышленной собственности с участием социальных предприятий по законодательству Российской Федерации.

Ключевые слова: интеллектуальная собственность, предпринимательский договор, результат интеллектуальной деятельности, социальное предпринимательство, договор коммерческой концессии, социальное предприятие.

Для цитирования: Баттахов П.П. Договоры о передаче исключительных прав на объекты промышленной собственности с участием социальных предприятий // Пробелы в российском законодательстве. 2021. T. 14. №3. C. 200-204.

\section{Agreements on the Transfer of Exclusive Rights to Objects of industrial Property with the Participation of Social Enterprises}

\section{@Battakhov P.P.}

Institute of State and Law of the Russian Academy of Sciences, Moscow, Russian Federation

Battakhov@mail.ru

\section{Abstract}

The article considers contractual designs aimed at transferring exclusive rights to industrial property. The problem of the contractual process was identified when concluding a contract on the transfer of a set of exclusive rights. Based on the study, a number of changes to Russian laws have been proposed. First of all, this applies to a commercial concession contract. The author proposes to amend the Civil Code of the Russian Federation by supplementing the article on commercial concession with the right of organizations that do not conduct commercial activities to conclude the same contracts on a general basis. The appropriateness of applying the classification of transactions into real and consensual ones in relation to this contract is justified. The peculiarities of transfer of the complex of exclusive rights to objects of industrial property with participation of social enterprises under the legislation of the Russian Federation are studied.

Keywords: intellectual property, business contract, result of intellectual activity, social enterprise, commercial concession contract, social enterprise.

For citation: Battakhov P.P. Agreements on the Transfer of Exclusive Rights to Objects of Industrial Property with the Participation of Social Enterprises // Gaps in Russian legislation. 2021. Vol. 14. №3. Pp. 200-204. (in Russ.).

\section{Введение}

Интеллектуальная собственность является одним из передовых институтов гражданского права. Поэтому в ускоренном темпе развиваются правоотношения данного направления. После распада Советского Союза резко возрос интерес к интеллектуальному праву в России. В последние годы хозяйствующими субъектами страны заключаются предпринимательские договоры по объектам промышленной собственности, и, соответственно, в судах интеллектуальной собственности рассматривается больше споров, чем по объектам интеллектуальной собственности. Законодательная база в последнее десятилетие усовершенствуется ученымицивилистами и практическими юристами. По сравнению с передовыми державами Россия довольно долгое время отставала в развитии объектов промышленной собственности. В настоящее время цивилизованные страны мира пополняют свои бюджеты за счет оборота интеллектуальной собственности. Поэтому нам необходимо развивать технологию на уровне передовых стран мира и даже перегонять их научный задел по всем интеллектуальным направлениям. Для этого нужно расширить перечень объектов интеллектуальной собственности в законодательстве страны.

\section{Понятие хозяйственного договора}

Предпринимательский договор - это соглашение хозяйствующих субъектов для реализации поставленных целей, задач, систематического получения прибыли путем реализации обещанных прав и выполнения обязан- 
ностей сторон. В настоящее время данный договор является самым востребованным среди юридических лиц, индивидуальных предпринимателей, граждан и регулируется Гражданским кодексом РФ. Настоящий договор - двигатель развития общества путем заключения между сторонами разных правоотношений; с помощью соглашения хозяйствующие субъекты продвигают предпринимательскую деятельность и развивают экономику страны.

Когда заключаются договора рассматриваемого вида, достигается правовая связь предпринимателя и внешнего мира, благодаря чему он может передавать свое имущество в пользования другим лицам, продавать товары, оказывать услуги, зарабатывая на этом. Для них характерны все свойства предпринимательской деятельности, но есть и свои особенности, которые делают их отличительными от бытовых договоров. Главное отличие заключается в ответственности, независимо от того, есть вина или нет ${ }^{1}$.

В России известные ученые юристы - понятие предпринимательского договора в своих работах по-разному излагают, например:

Как считает В. Ф. Яковлев, предпринимательский договор - это договор гражданско-правового характера, который должен отвечать общим правилам, независимо от его вида. Другими словами, это может быть любой гражданский или предназначенный для ведения бизнеса договор (аренда, подряд, купля-продажа, предоставление услуг и др.), который заключают между собой предприниматели. К таким договорам относятся следующие: продажи, аренды работающей компании, коммерческой концессии[1]

По мнению С. С. Занковского, предпринимательские договоры следует рассматривать как такие, при заключении которых передаются обязательства. Предпринимательские договоры отличаются от бытовых сделок тем, что их регулируют государство. Так, при продаже товара, бизнесмен может включить любые условия в договор, которые не противоречат действующим российским законам, если покупатель с ними согласился. Но качество товара должно отвечать обязательным требованиям, которые установило государство[2].

По мнению В.С. Белых, рассматриваемый вид договора является комплексным, потому что сочетает нормы частного и публичного права. Отсюда следует, что данное понятие является межотраслевым[3].

Как считает М.Н. Илюшина, в гражданском обороте и российских законах рассматриваемые договоры относятся к гражданско-правовым, они устанавливают требования, которые определены изначально. Юридические литературные источники содержат группу критериев, которые указывают именно на предпринимательские договоры среди всех гражданско-правовых[4].

Предпринимательским, как считает И.В. Каблашова, нужно считать такой договор, который стороны заключают для бизнеса. Это компромиссное решение, к которому пришли стороны. Данный документ - закрепление обязательств за каждой из сторон в отношении результата, для достижения чего проводится сделка. Другими словами, предпринимательский договор - это документ

\footnotetext{
${ }^{1}$ Предпринимательское (хозяйственное) право: учебник /[Вознесенская Н.Н. и др.]; под ред. В.В.Лаптева, С.С. Занковского Рос.акад.наук, Ин-т государства и права, Акад. правовой ун-т. -М.: Волтерс Клувер. 2006.-560с.
}

с решениями, принимаемыми бизнесменами в процессе своей работы².

Подводя итог высказываний известных ученых, следует констатировать, что развитие предпринимательских отношений в стране идет по правильному пути прогресса хозяйствующих организаций.

В советское время не было предпринимательских отношений, после образования нового государства в законодательстве страны появились разные договоры предпринимательской деятельности, которые регулируются Гражданским кодексом РФ. В хозяйственном обороте объектов промышленной собственности появились договоры предпринимательской деятельности, которые можно разделить на два блока:

1. Договоры по отчуждению объектов промышленной собственности (об отчуждении исключительного права на промышленные объекты, промышленных объектов в составе компании, когда он продается, передача в залог исключительных прав на промышленные объекты).

2. Договоры, в соответствии с которыми передаются исключительные права на промышленные объекты (лицензионный, коммерческой концессии, аренды и доверительного управления предприятием, как формы договорных отношений, чтобы вовлечь промышленные объекты в хозяйственный оборот компании).

\section{Договор коммерческой концессии в современном Российском праве}

Другие страны при торговле на мировом рынке уже дано применяют механизмы, которые позволяют компании или индивидуальному предпринимателю выходить на рынок, предоставляя исключительное право на ряд объектов интеллектуальной собственности[5]. Одно из ведущих мест среди договоров в сфере бизнеса, когда нужно обеспечит передачу исключительных прав, являются договоры коммерческой концессии. Согласно Гражданскому кодексу Российской Федерации, одна сторона данного вида договоров, которая имеет права, берет на себя обязательство передать пользователю, который является другой стороной, свои права для использования в предпринимательской деятельности. Это права на: товарный знак, ноу-хау для производства, знак обслуживания и другие объекты, которые содержит заключаемый сторонами договор. Стороны предлагаемого договора: компании, ведущие коммерческую деятельность, частные лица, зарегистрированные, как ИП ${ }^{3}$

По мнению В. Г. Варнавского, под концессией подразумевается система отношений, где в качестве одной стороны выступает государство или муниципальное образование, с другой - компания, как юридическое лицо или физическое лицо, деятельность которого зарегистрирована в качестве индивидуального предпринимателя. Данная система формируется согласно действующим российским законам и договору, заключенному, когда стороны пришли к соглашению. Ее предмет - это объект, право собственности, которое имеет государство (муниципальное образование) либо общественная услуга[6]

\footnotetext{
2 Каблашова И.В. Договор в сфере предпринимательства: Учебное пособие. Воронеж, 2008. С.82.

3 Гражданского кодекса Российской Федерации от 18 декабря 2006 г. N 230-Ф3 // Собрания законодательства Российской Федерации от 25 декабря 2006 г. N 52 (часть I) ст. 5496
} 
Как считает Е. А. Черепанова, под фрранчайзингом подразумевается форма ведения бизнеса, в основе которой система взаимоотношений, которые заключаются на основании соглашений о предоставлении за платное вознаграждение одной стороной (как правило, это известная компания, отлично зарекомендовавшая себя) другой стороне (компания или индивидуальный предприниматель) собственные средства. Данные средства индивидуализируют производимую продукцию, выполняемые работы или оказываемые услуги. К ним относят товарный знак, фирменный стиль, предпринимательские технологии или другую коммерческую информацию, при использовании которой принимаемая сторона сможет развиваться и укрепить свои позиции на рынке товаров и услуг. Сторона, которая передает данное право, берет на себя обязательство содействовать в развитии бизнеса принимающей стороны, предоставляя помощь технического характеры и консультации[7].

В основном предпринимательские договоры по объектам промышленной собственности заключаются только хозяйствующими субъектами. В России ряд комплексных договоров по объектам промышленной собственности заключаются по интересам хозяйствующих сторон. Например, в России одним из первых договоров коммерческой концессии стал договор между американской компанией «Макдоналдс» и российскими организациями. Смысл данного отношения сторон заключается в том, что это договор передачи исключительных прав российской компании, в рамках данного франчайзинга одна сторона (правообладатель) получает огромную выручку от передачи исключительных прав другому хозяйствующему субъекту.

На нефтяном рынке существует коммерческая организация ВР (транснациональная нефтегазовая компания), которая занимается продажей нефтепродуктов потребителям. Данная компания внедрилась на российский рынок недавно и с помощью передачи комплекса исключительных прав и заключения договора коммерческой концессии российским компаниям реализует свою бизнес-идею. С помощью вышеизложенного механизма ВР получает огромную прибыль, а другая сторона - российская компания - все расходы несет самостоятельно, британская компания передает только комплекс исключительных права.

В настоящее время на продаже интеллектуального труда стали больше зарабатывать успешные коммерческие компании. Некоммерческие организации участвуют во многих договорных отношениях, в том числе правоотношениях интеллектуальной собственности. Согласно законодательству РФ, потребительский кооператив не может заключать договор коммерческой концессии, поэтому предлагаю на возмездной основе передать коммерческим организациям комплекс исключительных прав для реализации подставленных целей и задач. В такой схеме в России реализовались проекты, связанные с предпринимательской деятельностью и реализацией социальных задач. Например, Общество Инвалидов имеет комплекс исключительных прав на массовую продажу (реализацию) костылей на рынке, организация должна передать комплекс исключительных прав коммерческим организациям по договору коммерческой концессии. Предлагаю для этого в ГК изменить и дополнить и дополнить данную статью таким понятием, как «непоименованный договор».

\section{Правовое регулирование социального предпринимательства в соере интеллектуальной собственности}

Социальное предпринимательство - это новое направление, соответственно, по правовому регулированию правоотношений в законодательстве страны был предпринят ряд мер. В общем в Российской Федерации поставлен высокий ориентир развития по двум основным направлениям: во-первых, социальные блоки и поднятие экономики, в целом данный толчок даст большой потенциал для улучшения жизни граждан и экономики страны.

Не так давно данный термин был закреплен в российском законодательстве, в котором под социальным предпринимательством понимается вид предпринимательской деятельности, направленный на решение общественно-полезных задач с целью решения различных социальных проблем[8]. Поэтому в последнее время с каждым годом динамично развивается социальное предпринимательство в России, и внесение нескольких судьбоносных статей в Ф3 «О развитии малого и среднего предпринимательства в Российской Федерации» сыграет большую роль в развитии данного направления в стране. Социальное предприятие может быть правообладателем комплекса исключительных прав, как сторона правоотношений оно отчуждает или передает права другим субъектам согласно законодательству РФ, и как субъект правоотношений предпринимательского права сталкивается в разных юридических казусах.

Социальным предприятием называет юридическое лицо, которое обладает определенным статусом, чтобы вести социальную деятельность. Такие предприятия решают социальные проблемы, что повышает качество жизни населения, и получают прибыль. От других хозяйствующих субъектов их отличает то, что социальные предприятия решают социальные задачи.

В решении проблем в социальной сфере страны социальные предприятия играют важную роль, поэтому государство должно способствовать их созданию. Их деятельность способствует подъему экономики страны. Так, в ходе свой работы бизнесмен получает поддержку в виде финансовых средств, с другой стороны государство гарантирует, что определенная программа в социальной сфере будет реализована в полной мере. В будущем реализация подобных проектов должна способствовать росту российской экономики, на федеральном уровне решать важные проблемы в социальной copepe[9].

Уже сегодня франчайзинг применяют в больше 70 секторах мировой экономики. Что касается Российской Федерации, то здесь он недостаточно распространен. Это объясняется наличием большого количества правовых и социально-экономических проблем. Применение в бизнесе договора коммерческой концессии позволит пользователям получить права их обладателя, добиться успеха в бизнесе, используя репутацию обладателя данных прав. Кроме этого, использование данного инструмент позволит снизить риски и затраты, которые могли бы иметь место без внедрения договора коммерческой концессии[10].

С развитием общества часто утрачивают законную силу связанные с предпринимательской деятельностью разные нормативные акты, соответственно, меняется и правовое регулирование предпринимательских 
отношений. Согласно законодательству РФ, предлагаю рассмотреть два случая.

Первое предложение. Согласно п. 1, ст. 4, Ф3 "О развитии малого и среднего предпринимательства в Российской Федерации", к субъектам малого и среднего предпринимательства относится потребительский кооператив. Значит, как социальное предприятие (некоммерческая организация) он обязан участвовать в предпринимательских отношениях, то есть заключать договор коммерческой концессии. В таком случае остальные некоммерческие организации тоже имеют право заключать данные соглашения.

Второе предложение касается изменения IV части Гражданского кодекса. Когда фрормируется интеллектуальная деятельность в начинающих организациях социального назначения (разработчики и правообладатели), в направлении исключительного права промышленной собственности необходимо провести серию мероприятий смягчающего характера. Например, уменьшить базовые требования к регистрации новых объектов промышленной собственности (по закону). Также необходимо немного преобразовать параметры соглашений, которые направлены на передачу исключительного права на объекты промышленной собственности (не фриксировать этот фракт в Роспатенте). В пункт 10 Постановления правительства РФ №941 внести следующую поправку:

- В соответствии с положениями подпунктов 21.1 и 21.2 пункта 1 приложения №1 в указанном правовом акте изложен порядок оплаты годовой пошлины за поддержание актуальности патента на полезную модель. Предлагается в указанном положении уточнить, что оплату нужно начать через три года с момента отправки запроса на регистрацию[11].

\section{Список литературы:}

1. Утина Е.О. Понятие и основные особенности предпринимательского договора и системы предпринимательских договоров // Актуальные проблемы правоведения. 2013.№2(38). С.72-78.

2. Занковский С.С. Предпринимательские договоры: понятие и проблемы //Экономика. Право. Общество. 2016. № 3 (7). С. 65-70.

3. Белых В.С. Правовое регулирование предпринимательской деятельности в России: Монография. М.,2005. C.432

4. Илюшина М.Н. Понятие, признаков и место предпринимательских договоров в системе гражданско-правовых договоров // Законы России: опыт, анализ, практик. №1. 2009. С.10.

5. Нэнси Черч. Знакомьтесь - франшизинг // Проблемы теории и практики управления. 1991. № 13. С 113-117; Разумнова И.И. «Франчайзинг» - система реализации товаров и услуг // США: экономика, политика, идеология. 1988. № 4. С. 22-29.

6. Варнавский В.Г. Государственно-частное партнёрство. - М.: ИМЭМО РАН, 2009. Том 1. - С. 50.

7. Черепанова Е.А. Франчайзинг в России: правовой аспект. - Екатеринбург: Уральское юридическое издательство, 2005. - С. 25.

8. Шпинев Ю.С. Социальное предпринимательство: вопросы правового регулирования //Пробелы в российском законодательстве. 2021. Т. 14. № 1. С. 40-45.

9. Баттахов П.П. Правовые аспекты социального предпринимательства в Российской Федерации //Тенденции развития науки и образования. 2020. № 68-7. С. 6-11.

\section{Заключение}

В стране динамичного развития интеллектуальной деятельности необходимо создавать условия для ученых, практикующих работников и хозяйствующих субъектов по всем сферам жизнедеятельности. В первые годы для получения результатов интеллектуальной деятельности нужна материальная поддержка со стороны государства, такая помощь будет полезна для прорывного развития интеллектуальной собственности в России. Необходимые изменения общественных интересов в стране ведут к появлению новых гражданских объектов собственности, зарождаются новые направления зарабатывания денежных средств, соответственно, государственные органы власти обязаны своими кардинальными решениями преобразовывать регулирующие нормы права на новом уровне. В данном случае для решения поставленных перед гражданами задач и для прорывного технологического развития необходимо внести изменения и дополнения в нормативно-правовые акты.

Таким образом, в России интеллектуальный труд в последнее время дает больше положительных моментов для развития экономики и решения социальных задач, такие соглашения интеллектуальной собственности дадут большой импульс развитию предпринимательской деятельности. Передача комплекса исключительных прав на результаты интеллектуальной деятельности набирает оборот. С помощью данного инструмента многие хозяйствующие субъекты без умственных усилий реализуют бизнес-проекты внутри государства и за его пределами. Необходимо изменить и дополнить ряд нормативно-правовых актов в соответствии с Парижской конвенцией по охране промышленной собственности и с Конституцией РФ.

\section{References:}

1. Utina E.O. The concept and main features of an entrepreneurial contract and the system of entrepreneurial contracts//Topical problems of law. 2013.№2(38). Page 72-78.

2. Zankovsky S.S. Business contracts: concept and problems//Economics. Right. Society. 2016. № 3 (7). Page 6570

3. Belykh V.S. Legal regulation of entrepreneurial activity in Russia: Monograph. M.,2005. Page 432

4. Ilyushina M.N. The concept, characteristics and place of business contracts in the system of civil law contracts//Laws of Russia: experience, analysis, practice. №1. 2009. Page 10.

5. Nancy Church. Meet -- franchising//Problems of management theory and practice. 1991. № 13. Page 113-117; Razumnova I.I. Franchising is a system for the sale of goods and services//USA: economics, politics, ideology. 1988. № 4. Page 22-29.

6. Varnavsky V.G. Public-private partnership. - M.: IMEMO RAS, 2009. Volume 1. - S. 50.

7. Cherepanova E.A. Franchising in Russia: legal aspect. - Yekaterinburg: Ural Law Publishing House, 2005. - P. 25.

8. Shpinev Yu.S. Social entrepreneurship: issues of legal regulation//Gaps in Russian legislation. 2021. T. 14. № 1. Page 40-45.

9. Battakhov P.P. Legal aspects of social entrepreneurship in the Russian Federation//Trends in the development of science and education. 2020. № 68-7. Page 6-11. 
10. Джинджолия К.К. Договор коммерческой концессии и франчайзинг в экономической деятельности: проблемы регистрации и исполнения // Право и экономика. N 9. 2020. C. 49-55.

11. Постановления опубликованы в Собрании законодательства Российской Федерации от 22 декабря 2008 г. N 51 ст. 6170
10. Ginjolia K.K. Commercial concession agreement and franchising in economic activities: problems of registration and execution//Law and economy. N 9. 2020. Page 49-55.

11. Resolutions published in the Collection of Legislation of the Russian Federation dated December 22, 2008 N 51 Art. 6170

\section{Рецензия}

на статью «Договоры о передаче исключительных прав на объекты промышленной собственности с участием социальных предприятий» старшего научного сотрудника сектора предпринимательского и корпоративного права Института государства и права Российской академии наук, к.ю.н., Баттахова П.П.

В статье рассматриваются договорные конструкции, направленные на передачу исключительных прав на объекты промышленной собственности. Автор анализирует проблему договорного процесса при заключении договора о передаче комплекса исключительных прав. Обоснована целесообразность применения классификации сделок на реальные и консенсуальные в отношении данного договора. Исследуются особенности о передаче комплекса исключительных прав на объекты промышленной собственности с участием социальных предприятий по законодательству Российской Федерации.

Актуальность статьи не вызывает сомнений, поскольку тема договоров о передаче исключительных прав на объекты промышленной собственности является одной из основных важнейших задач, особенно сейчас, в цифровизации всей сферы интеллектуальной собственности.

Объектом исследования являются гражданские правоотношения, регулирующие права интеллектуальной собственности.

Научная новизна работы проявляется в ряде теоретических и практических выводов, сделанных в результате исследования.

Статья хорошо структурирована, написана четким и понятным языком, выводы логичны. При написании статьи автором использованы необходимые литературные источники, нормативный материал.

В целом научная статья Баттахова П.П. отвечает предъявленным требованиям и может быть опубликована в научном издании, в т.ч. входящим в перечень ВАК.

Главный научный сотрудник ИГП РАН, и.о. заведующего сектором, Заслуженный юрист Российской Федерации, доктор юридических наук, профессор С.С.Занковский

Статья прошла проверку системой «Антиплагиат»; оригинальность текста - 91,24\%

\section{СВЕДЕНИЯ ОБ АВТОРЕ}

Баттахов Петр Петрович, канд. юрид. наук, старший научный сотрудник сектора предпринимательского и корпоративного права ФГБУН Институт государства и права РАН.
ABOUT THE AUTHOR

Battakhov Pyotr Petrovich, Candidate of Legal Sciences, Senior Researcher in the Business and Corporate Law Sector, FSBUN Institute of State and Law of the Russian Academy of Sciences. 